\title{
Spiking-Bursting Activity in the Thalamic Reticular Nucleus Initiates Sequences of Spindle Oscillations in Thalamic Networks
}

\author{
M. BAZHENOV, ${ }^{1}$ I. TIMOFEEV, ${ }^{2}$ M. STERIADE, ${ }^{2}$ AND T. SEJNOWSKI ${ }^{1,3}$ \\ ${ }^{1}$ Howard Hughes Medical Institute, The Salk Institute, Computational Neurobiology Laboratory, La Jolla, California 92037; \\ ${ }^{2}$ Laboratory of Neurophysiology, School of Medicine, Laval University, Quebec G1K 7P4, Canada; and ${ }^{3}$ Department of \\ Biology, University of California San Diego, La Jolla, California 92093
}

Received 26 January 2000; accepted in final form 11 April 2000

\begin{abstract}
Bazhenov, M., I. Timofeev, M. Steriade, and T. Sejnowski. Spiking-bursting activity in the thalamic reticular nucleus initiates sequences of spindle oscillations in thalamic networks. J Neurophysiol 84: 1076-1087, 2000. Recent intracellular and local field potential recordings from thalamic reticular (RE) neurons in vivo as well as computational modeling of the isolated RE nucleus suggest that, at relatively hyperpolarized levels of membrane potentials, the inhibitory postsynaptic potentials (IPSPs) between RE cells can be reversed and $\gamma$-aminobutyric acid-A $\left(\mathrm{GABA}_{\mathrm{A}}\right)$-mediated depolarization can generate persistent spatio-temporal patterns in the RE nucleus. Here we investigate how this activity affects the spatio-temporal properties of spindle oscillations with computer models of interacting $\mathrm{RE}$ and thalamocortical (TC) cells. In a one-dimensional network of RE and TC cells, sequences of spindle oscillations alternated with localized patterns of spike-burst activity propagating inside the RE network. New sequences of spindle oscillations were initiated after removal of $I_{\mathrm{h}}$-mediated depolarization of the TC cells. The length of the interspindle lulls depended on the intrinsic and synaptic properties of RE and TC cells and was in the range of 3-20 s. In a two-dimensional model, $\mathrm{GABA}_{\mathrm{A}}$-mediated $2-3 \mathrm{~Hz}$ oscillations persisted in the $\mathrm{RE}$ nucleus during interspindle lulls and initiated spindle sequences at many foci within the RE-TC network simultaneously. This model predicts that the intrinsic properties of the reticular thalamus may contribute to the synchrony of spindle oscillations observed in vivo.
\end{abstract}

\section{IN T R O D U C T I O N}

GABAergic thalamic reticular (RE) cells contribute to a variety of oscillatory activities in the thalamus during sleep. One of the most important is the spindle oscillation, which is generated as a result of interaction between thalamocortical (TC) and RE cells (Krosigk et al. 1993; Steriade and Llinás 1988; Steriade et al. 1985, 1990, 1993). Spindle oscillations are sequences of 7-14 Hz bursting activity lasting 1-3 s. They recur every 5-15 $\mathrm{s}$ and are terminated by $\mathrm{Ca}^{2+}$-induced cAMP up-regulation of $I_{\mathrm{h}}$ current in TC cells (Bal and McCormick 1996; Budde et al. 1997; Lüthi and McCormick 1999; Lüthi et al. 1998). Extracellular recordings from a deafferented RE nucleus in vivo have demonstrated that the RE network not only contributes to the spindle activity in the intact thalamus but can itself generate oscillations in the spindle frequency range (Steriade et al. 1987).

Lateral connections between RE cells are mediated by the

\footnotetext{
Address for reprint requests: M. V. Bazhenov, Howard Hughes Medical Institute, The Salk Institute, Computational Neurobiology Laboratory, 10010 North Torrey Pines Rd., La Jolla, CA 92037.
}

$\gamma$-aminobutyric acid-A $\left(\mathrm{GABA}_{\mathrm{A}}\right)$ synapses, which have a $\mathrm{Cl}^{-}$ reversal potential at around $-71 \mathrm{mV}$ (Ulrich and Huguenard 1997); the resting membrane potential of RE neurons may be even more hyperpolarized (Ulrich and Huguenard 1996). Recent intracellular and local field potential recordings from RE cells as well as a computer model of RE neurons have shown that under these conditions, activation of the lateral GABAergic synapses between RE cells leads to depolarization and may trigger a $\mathrm{Ca}^{2+}$ spike followed by the burst of $\mathrm{Na}^{+}$spikes (Bazhenov et al. 1999). In the computer model of the isolated $\mathrm{RE}$ nucleus of thalamus, $\mathrm{GABA}_{\mathrm{A}}$-mediated depolarization was responsible for patterns of spike-burst activity propagating through the network of RE cells or persisting in the form of the complex spatio-temporal patterns (Bazhenov et al. 1999).

We have used in vivo recordings and a computer model of the RE-TC network to investigate the role of spiking-bursting activity in the RE nucleus for initiating sequences of spindle oscillations. We found that when RE cells were sufficiently hyperpolarized, each sequence of spindle oscillations was followed by waves of activity that persisted in the RE network during interspindle lulls and initiated new spindle sequences.

\section{METHODS}

\section{In vivo recordings}

In vivo experiments were conducted on 47 unilaterally decorticated cats and 52 cats with intact thalamocortical connections. All animals were maintained under either ketamine and xylazine [10-15 and 2-3 $\mathrm{mg} / \mathrm{kg}$, intramuscularly (im)] or pentobarbital sodium $(30-35 \mathrm{mg} / \mathrm{kg}$ ) anesthesia. In addition, tissues to be incised and pressure points were infiltrated with lidocaine. The electroencephalogram (EEG) from the intact hemisphere was continuously recorded and additional doses of anesthetics were administered at the slightest tendency toward an increase in frequency and decrease in amplitude of EEG field potentials. Cats were paralyzed with gallamine triethiodide and artificially ventilated to the end-tidal $\mathrm{CO}_{2}$ of $3.5-3.8 \%$. The heartbeat was monitored and kept constant (acceptable range, $90-110$ beats/min). Body temperature was maintained at $37-39^{\circ} \mathrm{C}$. Glucose saline $[5 \%$ glucose, $10 \mathrm{ml}$ intraperitoneally (ip)] was given every 3-4 h during the experiments, which lasted for 8-14 h. The stability of intracellular recordings was ensured by cisternal drainage, bilateral pneumothorax, hip suspension, and by filling the hole made in the skull with a

\footnotetext{
The costs of publication of this article were defrayed in part by the payment of page charges. The article must therefore be hereby marked "advertisement" in accordance with 18 U.S.C. Section 1734 solely to indicate this fact.
} 
solution of agar-agar (4\%). All experimental procedures were performed according to Canadian guidelines. For microelectrode recordings from TC and RE neurons, the surface of the cortex that corresponds to the anterior half of the marginal and suprasylvian gyri was cauterized with silver nitrate. The cortex and white matter were removed by suction until the head of the caudate nucleus was exposed. Micropipettes were then lowered stereotaxically through the head of the caudate nucleus at anterior plane A 13 to reach the rostrolateral sector of the RE nucleus or at A 10-11 to record from ventrolateral (VL) neurons. Intracellular recordings were made with conventional sharp electrodes filled with a $2.5 \mathrm{M}$ solution of potassium acetate (DC resistance of 30-70 M $\Omega$ ). Stable intracellular recordings had resting membrane potential more negative than $-55 \mathrm{mV}$ and overshooting action potentials. Stimuli to the VL nucleus and to motor cortical area 4 were delivered with variable durations $(0.05-0.2 \mathrm{~ms})$ and intensities $(0.05-0.3 \mathrm{~mA})$. Single- and multi-unit activity were recorded by means of tungsten microelectrodes (resistance 7-10 M $\Omega$ ). At the end of the experiments, the animals were given a lethal dose of pentobarbital.

\section{Model: Intrinsic currents}

We examined single-compartment models of TC and RE cells which included voltage- and calcium-dependent currents described by Hodgkin-Huxley kinetics

$$
C_{m} \frac{d V}{d t}=-g_{L}\left(V-E_{L}\right)-I^{\mathrm{int}}-I^{\mathrm{syn}}
$$

where $C_{m}=1 \mu / \mathrm{cm}^{2}$ is the membrane capacitance, $g_{L}$ is the leakage conductance $\left(g_{L}=0.01 \mathrm{mS} / \mathrm{cm}^{2}\right.$ for TC cell and $g_{L}=0.05 \mathrm{mS} / \mathrm{cm}^{2}$ for RE cell), $E_{L}$ is the reversal potential $\left(E_{L}=-70 \mathrm{mV}\right.$ for TC cell and $E_{L}=-77 \mathrm{mV}$ for $\mathrm{RE}$ cell), $I^{\text {int }}$ is a sum of active intrinsic currents $\left(I_{j}^{\mathrm{int}}\right)$, and $I^{\mathrm{syn}}$ is a sum of synaptic currents $\left(I_{j}^{\mathrm{syn}}\right)$. The area of an RE cell was $S_{\mathrm{RE}}=1.43 \times 10^{-4} \mathrm{~cm}^{2}$ and the area of a TC cell was $S_{\mathrm{TC}}=2.9 \times 10^{-4} \mathrm{~cm}^{2}$.

For both RE and TC cells, we considered a fast sodium current, $I_{\mathrm{Na}}$, a fast potassium current, $I_{\mathrm{K}}$ (Traub and Miles 1991), a low-threshold $\mathrm{Ca}^{2+}$-dependent current, $I_{\mathrm{T}}$ ( Huguenard and McCormick 1992; Huguenard and Prince 1992), and a potassium leak current, $I_{\mathrm{KL}}=$ $g_{\mathrm{KL}}\left(V-E_{\mathrm{KL}}\right)$. A model of hyperpolarization-activated cation current $I_{\mathrm{h}}$ (McCormick and Pape 1990), taking into account both voltage and $\mathrm{Ca}^{2+}$ dependencies (Destexhe et al. 1996), was also included in TC cells. The voltage-dependence is described by the first-order kinetics of transitions between closed $C$ and open $O$ states of the channels without inactivation

$$
C \underset{\beta}{\leftrightarrow} O
$$

where $\alpha(V), \beta(V)$ are the voltage-dependent transition rates.

The $\mathrm{Ca}^{2+}$-dependence is based on higher order kinetics involving a regulation factor $P$. The binding of the $\mathrm{Ca}^{2+}$ molecules with unbound form of the regulation factor $P_{0}$ leads to the bound form of $P_{1}$. At the next step, $P_{1}$ binds to the open state of the channel $O$ that produces the locked form $O_{L}$

$$
P_{0}+2 \mathrm{Ca}^{2+} \underset{k_{2}}{\stackrel{k_{1}}{\leftrightarrow}} P_{1}, \quad O+P_{1} \underset{k_{4}}{\stackrel{k_{3}}{\leftrightarrow}} O_{L}
$$

Both the open and locked states of the channels contribute to the $I_{\mathrm{h}}$ current

$$
I_{\mathrm{h}}=g_{\max }\left([O]+k\left[O_{L}\right]\right)\left(V-E_{h}\right)
$$

The expressions for voltage- and $\mathrm{Ca}^{2+}$-dependent transition rates for all currents are given in Bazhenov et al. 1998.

\section{Model: Synaptic currents}

All synaptic currents were calculated according to

$$
I_{\text {syn }}=g_{\text {syn }}[O]\left(V-E_{\text {syn }}\right)
$$

where $g_{\text {syn }}$ is the maximal conductivity, $[O](t)$ is the fraction of open channels, and $E_{\mathrm{syn}}$ is the reversal potential. $E_{\mathrm{AMPA}}^{\mathrm{syn}}=0 \mathrm{mV}$ for $\alpha$-amino-3-hydroxy-5-methyl-4-isoxazolepropionic acid (AMPA) receptors, $E_{\mathrm{GABAA}}^{\mathrm{syn}}=-70 \mathrm{mV}$ for $\mathrm{GABA}_{\mathrm{A}}$ receptors in $\mathrm{RE}$ cells and $E_{\mathrm{GABAA}}^{\mathrm{syn}}=-80 \mathrm{mV}$ for $\mathrm{GABA}_{\mathrm{A}}$ receptors in $\mathrm{TC}$ cells (Ulrich and Huguenard 1997), and $E_{\mathrm{GABAB}}^{\mathrm{syn}}=-95 \mathrm{mV}$ for $\mathrm{GABA}_{\mathrm{B}}$ receptors.

$\mathrm{GABA}_{\mathrm{A}}$ and AMPA synaptic currents were modeled by first-order activation schemes (Destexhe et al. 1994c). GABA $_{B}$ receptors were modeled by a higher order reaction scheme that took into account activation of $\mathrm{K}^{+}$channels by G-protein (Destexhe et al. 1994c, 1996; Dutar and Nicoll 1988). The equations for all synaptic currents are given in Bazhenov et al. 1998.

\section{Network geometry}

We simulated three network models: 1) a one-dimensional chain of $100 \mathrm{RE}$ cells; 2) a one-dimensional chain of $2 \times 100 \mathrm{RE}$ and TC cells; and 3) a two-dimensional network of $2 \times 25 \times 25 \mathrm{RE}$ and TC cells. In the first model, each RE cell $x_{i}(i \in[1, M], M=100)$ was connected with its eight nearest neighbors $\left(x_{j}, j \in[i-4, i-1] \cup[i+1, i+\right.$ 4]) with $\mathrm{GABA}_{\mathrm{A}}$ synapses. In the second model, we additionally considered $\mathrm{RE} \rightarrow \mathrm{TC}\left(\mathrm{GABA}_{\mathrm{A}}+\mathrm{GABA}_{\mathrm{B}}\right)$ and $\mathrm{TC} \rightarrow \mathrm{RE}(\mathrm{AMPA})$ connections. The diameters of the connection fan out were nine cells for all types of synapses. In a two-dimensional RE-TC model, each RE (TC) cell $x_{i, j}(i, j \in[1, M])$ was connected with all RE-TC (RE) cells inside a radius of four cells $\left[x_{i^{\prime}, j^{\prime}},\left(\left(i-i^{\prime}\right)^{2}+\left(j-j^{\prime}\right)^{2}\right) \leq 4\right]$. Both flow (network is reflected symmetrically relative to the left or right boundary points: $V_{j}=V_{j^{\prime}}$, for $j^{\prime}=-j+1$ if $j \in[-3,0]$, and $j^{\prime}=2 M-j+1$ if $j \in[M+1, M+4]$ ) and periodic (network is closed into a loop: $V_{j}=V_{j^{\prime}}$, for $j^{\prime}=M+j$ if $j \in[-3,0]$, and $j^{\prime}=$ $j-M$ if $j \in[M+1, M+4])$ boundary conditions were used in the one-dimensional models. Only flow boundary conditions $\left(V_{k, 1}=V_{k^{\prime}, l^{\prime}}\right.$ with the same rules for calculation $k^{\prime}$ and $l^{\prime}$ as for the 1D model) were used in a two-dimensional RE-TC model. Some of the intrinsic parameters of the neurons in the network $\left(g_{\mathrm{KL}}, g_{\mathrm{h}}\right.$ for TC cells and $g_{\mathrm{KL}}$ for RE cells) were initialized with some random variability (variance $\sigma \sim 10 \%$ ) to insure the robustness of the results (Bazhenov et al. 1998).

\section{Computational methods}

All simulations described in the paper were performed using fourthorder Runge-Kutta $[\mathrm{RK}(4)]$ method and in some cases embedded Runge-Kutta [RK6(5)] method (Enright et al. 1995) with a time step of $0.04 \mathrm{~ms}$. Source $\mathrm{C}++$ code was compiled on a Alpha Server 2100A (5/300) using DEC C + + compiler. A simulation with $100 \mathrm{RE}$ cells took 6 min and a network with $2 \times 100$ RE-TC cells took $28 \mathrm{~min}$ of computer time to simulate $1 \mathrm{~s}$ of real time.

\section{R E S U L T S}

\section{Synchronizing patterns of thalamic oscillations in vivo}

In the first series of experiments, we examined the spontaneous activity of RE and TC neurons of decorticated cats. Decortication removes the cortical depolarizing projections to the thalamus and leaves intact intrinsic thalamic activities (Timofeev and Steriade 1997). Out of 106 RE neurons, 68 $(64.2 \%)$ showed spindle oscillations repeated every 5-30 s. In $28 \mathrm{RE}$ neurons, we found single or double spike bursts of action potentials (interburst intervals around $0.3-0.5 \mathrm{~s}$ ) during 
Reticular thalamic neuron
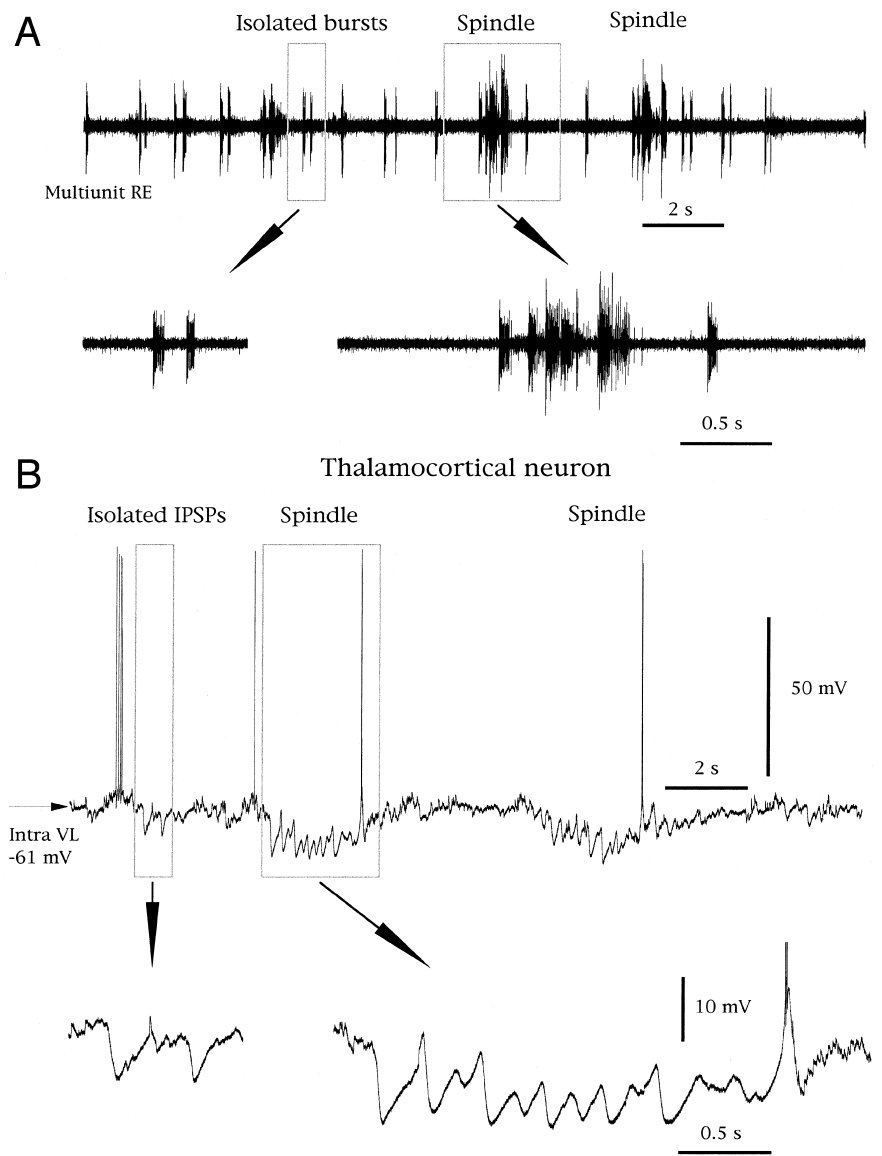

FIG. 1. Cellular patterns of spontaneous activity of thalamic neurons in decorticated cats. Ketamine-xylazine anesthesia. A: multi-unit activity recorded from thalamic reticular nucleus. Cellular activity was characterized by spontaneous spindles and isolated bursts and/or pairs of bursts during interspindle lulls. $B$ : intracellular activity recorded from thalamo-cortical VL neuron. Two types of spontaneous IPSPs were found: spindle oscillations, characterized by rhythmic barrages of IPSPs, and singlet or doublets of IPSPs occurring during interspindle lulls. In $A$ and $B$, framed fragments are expanded below, as indicated by arrows.

interspindle lulls (Fig. 1A). A reflection of such burst activity of RE neurons was found in TC neurons recorded from $\mathrm{VL}$ and LP nucleus of decorticated cats (Fig. $1 B$ ). Spindles were characterized by rhythmic IPSPs at $7-10 \mathrm{~Hz}$ and single or double IPSPs were found between spindles. The amplitude and duration of these isolated IPSPs were very similar to the amplitude and duration of unitary IPSPs recorded during spindles. These data indicate that the large-amplitude IPSPs in TC neurons recorded during interspindle lulls originated from cells in the RE nucleus rather than local circuit intrathalamic interneurons. In approximately 10,000 spontaneous spindles recorded intracellularly from TC neurons in vivo, only a few exhibited high-frequency spike bursts within the first three IPSPs within spindle sequences. This suggests that TC neurons are only passively involved in at least the initial part of the spindle sequences. The isolated RE nucleus is able to maintain spindlerelated activities (Steriade et al. 1987) and in the large-scale two-dimensional RE network these activities can be mediated by depolarizing $\mathrm{GABA}_{\mathrm{A}}$ IPSPs that directly trigger a lowthreshold spike (Bazhenov et al. 1999). These data suggest that the RE nucleus has a leading role in the onset of spindle-related activities and that TC neurons mainly reflect, amplify, and synchronize spindles within the thalamus and the full thalamocortico-thalamic loop.

Field potential, single-, multi-unit, and intracellular recordings performed in intact cortex animals under barbiturate anesthesia showed, as previously described (Contreras et al. 1996), spindles that were often synchronized at different recording sites. However, this was not always observed. Sometimes, periods of synchronous spindle-related activities were intermixed with periods of spindles synchronized only locally. Short-range synchronization of spindles was observed as relatively large-amplitude field potentials recorded at one site and not accompanied by similar field potentials and/or related cellular activities recorded at remote sites (Fig. 2). Detailed examination of recordings showed that the loss of spindle synchrony between TC neurons from VL nucleus of thalamus and cortical field potentials from area 4 occurs when thalamic neurons received barrages of excitatory postsynaptic potential (EPSPs) presumably of cerebellar origin (Timofeev and Steriade 1997; Fig. 2, bottom). These EPSPs affected not only the recorded thalamic neuron, but also functionally neighboring cells (Rispal-Padel et al. 1987a,b) and elicited depolarization sufficient to shift the onset of spindle and thus to disrupt long-range synchronization. Below, we present a model of RE-TC network where spindles are initiated by bursting activity of RE neurons and we study the role of network connectivity, membrane potentials, and intrinsic and synaptic currents in the generation, maintenance, and periodicity of spindles.

\section{Isolated RE network}

We first simulated an isolated RE network hyperpolarized below the $\mathrm{Cl}^{-}$reversal potential. At the resting membrane potential of about $-75 \mathrm{mV}$, the low-threshold $\mathrm{Ca}^{2+}$ current in the RE cells was deinactivated. Bursts of spikes in presynaptic

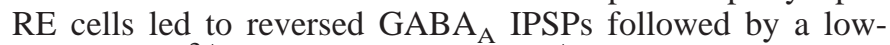
threshold $\mathrm{Ca}^{2+}$ spike and a burst of $\mathrm{Na}^{+}$spikes in postsynaptic $\mathrm{RE}$ cells. The temporal inactivation of the low-threshold $\mathrm{Ca}^{2+}$ current in an RE cell after a burst discharge prevented oscillations from persisting in the cell (see details in Bazhenov et al. 1999).

In Fig. 3, the RE cell \#1 from the network of 100 cells was stimulated with an AMPA EPSP at $t=0$. The wave of activity mediated by $\mathrm{GABA}_{\mathrm{A}}$ depolarization propagated with constant velocity about 70 cells/s (Fig. 3Al) and about 125 cells/s in another network (Fig. 3A2). Clusters of a few RE cells were activated simultaneously, whose size depended on the radius of synaptic interconnections (see Fig. 3, B1 and B2). The speed of activity propagation increased with the radius of $\mathrm{GABA}_{\mathrm{A}}$ coupling and the strength of $\mathrm{GABA}_{\mathrm{A}}$ synapses; however, it reached a maximum at $g_{\mathrm{GABAA}}=0.25-0.35 \mu \mathrm{S}$ (Bazhenov et al. 1999).

When the RE cells were almost identical, spiking-bursting activity propagated through the network and terminated at the boundary. When there was strong variability in the resting membrane potential of RE cells of 5-7 mV (Fig. 3C), some of the neurons showed spontaneous bursts of $\mathrm{Na}^{+}$spikes that randomly initiated clusters of activity traveling through the RE network. These clusters were terminated either at the boundaries or as a result of collision with other clusters. 


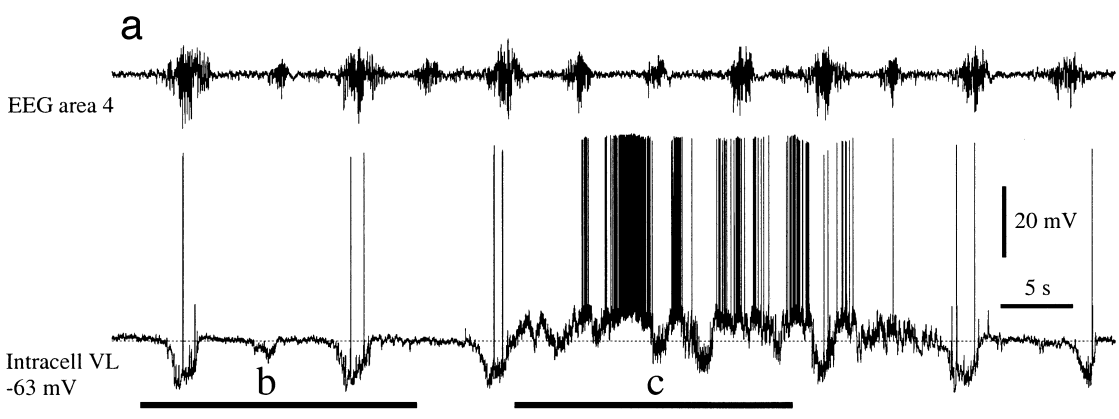

b
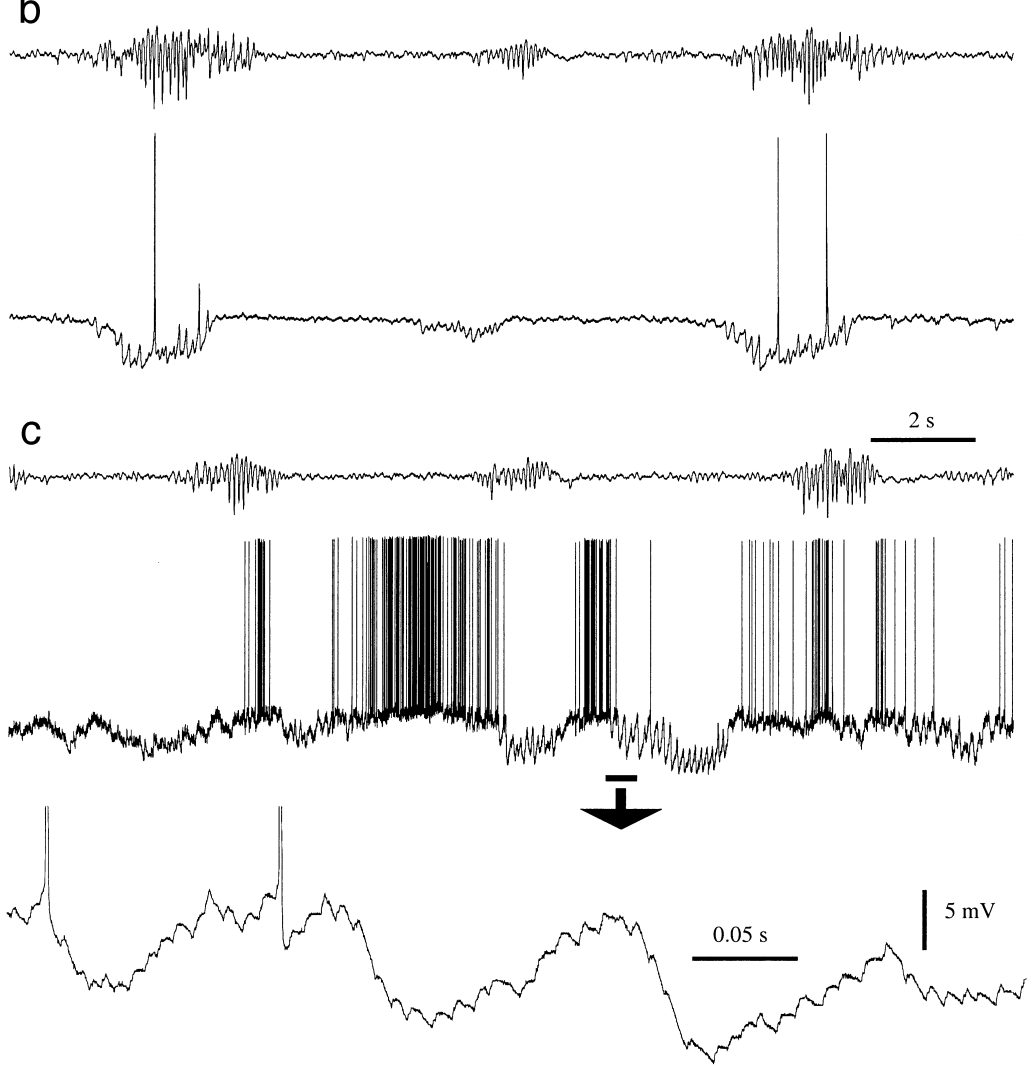

FIG. 2. Synaptic depolarization of TC neurons disrupts spindle synchrony in thalamocortical pathway. Barbiturate anesthesia. Field potential from the depth of area 4 and intracellular activity of thalamocortical (TC) neuron from VL nucleus. Parts marked by horizontal lines are expanded below. At the resting membrane potential, TC neuron produced spindles, almost simultaneously with spindles in the corresponding cortical area. Barrages of excitatory postsynaptic potentials (EPSPs), presumably of cerebellar origin (see Timofeev and Steriade 1997), depolarized the TC neuron and spindle oscillations were no longer synchronous with cortical EEG spindles.

\section{Spindle oscillations in RE-TC network}

In a one-dimensional chain of RE-TC cells, external AMPA stimulation led to a sequence of spindle (about $10 \mathrm{~Hz}$ ) oscillations involving both RE and TC cells. Once started, spindle oscillations lasted about 2-3 s and were terminated by depolarization of TC cells following calcium-induced cAMP upregulation of hyperpolarization-activated cation current, $I_{\mathrm{h}}(\mathrm{Bal}$ and McCormick 1996; Budde et al. 1997; Lüthi et al. 1998). The hyperpolarization of $\mathrm{RE}$ cells below the $\mathrm{Cl}^{-}$reversal potential did not change the properties of spindle sequences; however, after each spindle sequence a few localized patterns propagated through the RE network (Fig. 4). These patterns evoked IPSPs in TC cells but were not able to trigger a low-threshold $\mathrm{Ca}^{2+}$ spike and $\mathrm{Na}^{+}$spikes in cells that were depolarized right after last spindle sequence. This refractoriness was the result of deinactivation of the low-threshold $\mathrm{Ca}^{2+}$ current in TC neurons at relatively depolarized levels of membrane potential.

The properties of the spatio-temporal patterns of spindle oscillations depended on the level of membrane potential in TC cells. At more hyperpolarized levels, a "continuous" pattern of $10-\mathrm{Hz}$ oscillations of similar duration in different TC cells was observed (Fig. 4A). Depolarizing the TC cells in the RE-TC network by about $2-3 \mathrm{mV}$ changed the spatial structure of the spindle sequences. In Fig. $4 B$, the initial stimulation led to a single wave propagating through RE-TC network that initiated local sequences of spindle oscillations at different foci. Almost all cells were involved in $10-\mathrm{Hz}$ oscillations by $2 \mathrm{~s}$; different network foci terminated at different times.

Figure $4 C$ shows the time traces of five different TC cells and Fig. $4 D$ shows the average membrane potential calculated over $10 \mathrm{TC}$ cells at 10 equally spaced sites. In the relatively hyperpolarized TC network (Fig. 4A), the spindle oscillations at two sites were delayed by $\Delta T=L / N$, where $V$ is a speed of wave propagation and $L$ is the distance between the sites. After depolarization (Fig. 4B), the duration of spindle oscillations in different foci varied widely and spindles were initiated at random times that depended on the local membrane potentials of RE and TC cells. 
A1

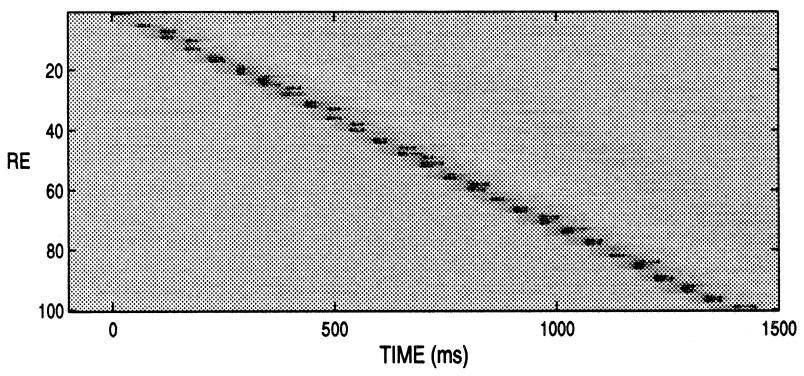

B1

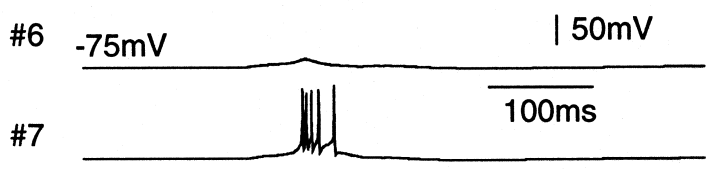

\#8

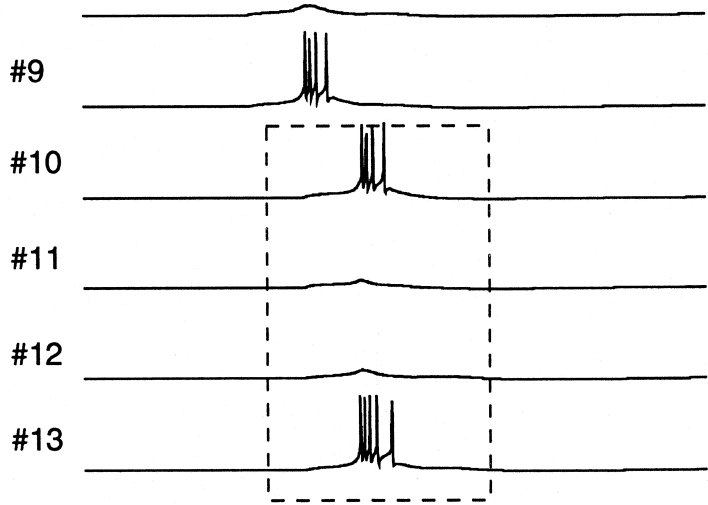

$\# 14$

$\# 15$

$\# 16$

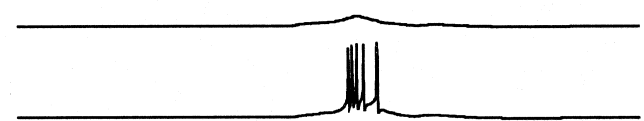

C1

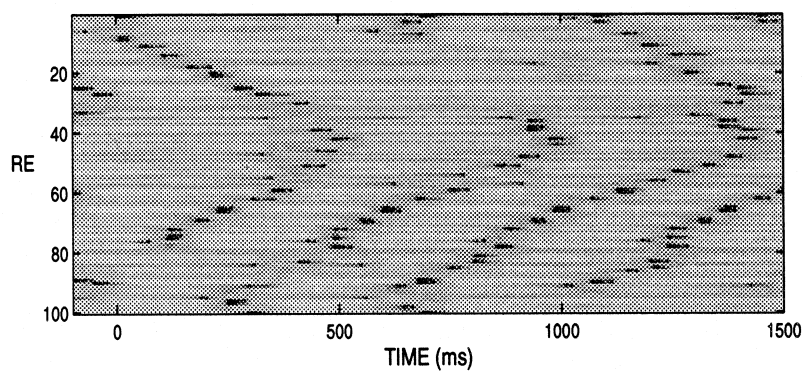

$\mathrm{A} 2$

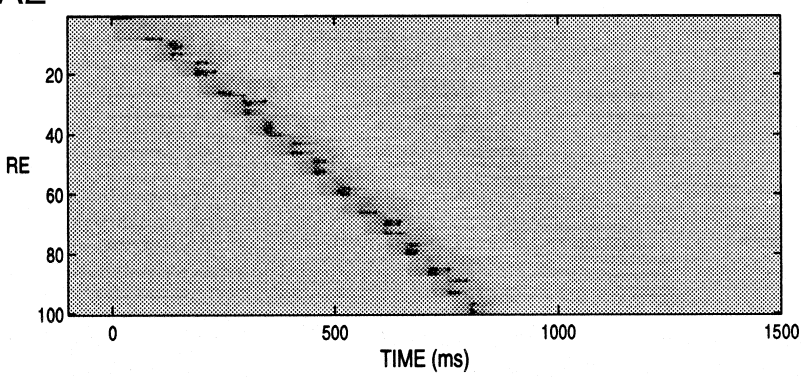

B2

\section{\#6 $\quad-75 \mathrm{mV}$}

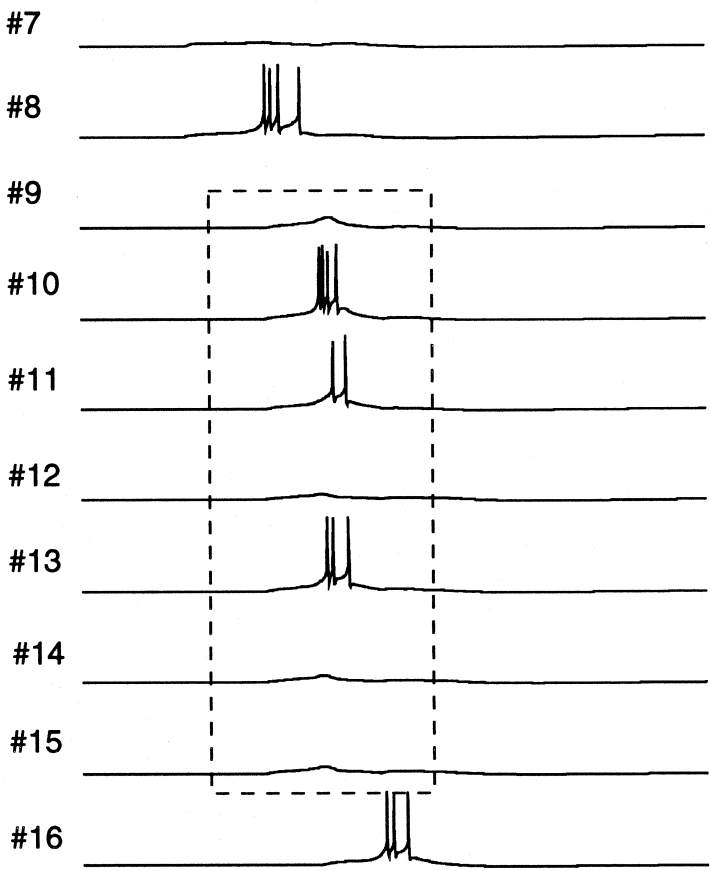

C2

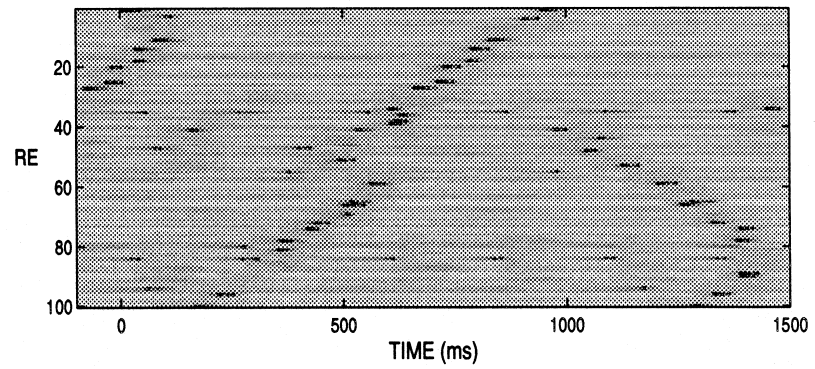

FIG. 3. Patterns of spiking-bursting activity in the isolated RE network with two different radii $(N)$ of synaptic interconnections: $n=4$ at the left and $n=7$ cells at the right. Average resting potential of RE cells was $-75 \mathrm{mV}$. A: cell \#1 from the network of 100 cells was stimulated at the time instant $t=0$ (left upper corner of the panel). A single localized pattern is propagated with constant velocity. $B: 11$ neighboring RE cells from the network. Dashed lines indicate a cluster of cells activated simultaneously. $C$ : network of RE cells with strong variability of the rest membrane potentials. Some RE cells fired spontaneously and initiated localized waves of spiking-bursting activity.

\section{Initiation of spindle oscillations}

In a network with $2 \times 100$ RE-TC neurons and finite boundary conditions, the localized waves propagating through the RE network terminated at the boundaries after about 1-2 s. With periodic boundary conditions, the localized patterns in the isolated RE network could propagate infinitely around the network circuit (not shown). However, in the RE-TC model, the slow repolarization of TC cells eventually deinactivated the low-threshold $\mathrm{Ca}^{2+}$ current. As the TC membrane potential hyperpolarized below about $-64 \mathrm{mV}$, the RE-evoked IPSPs 
A
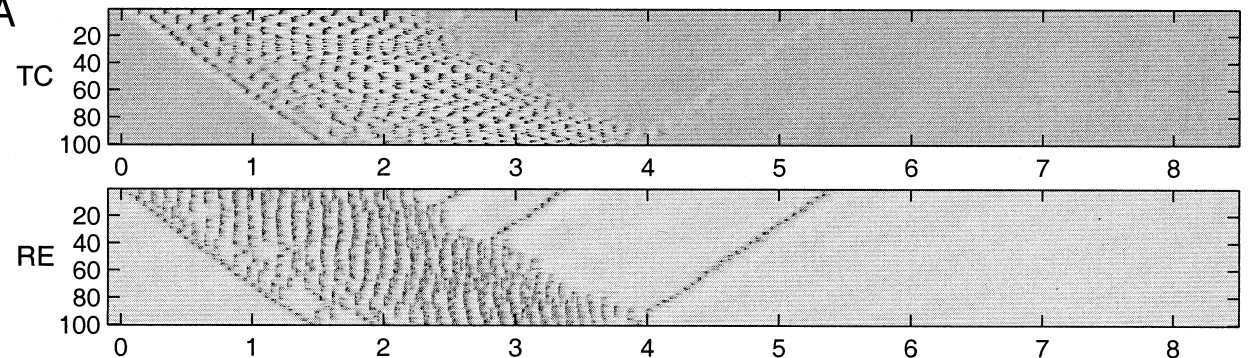

B

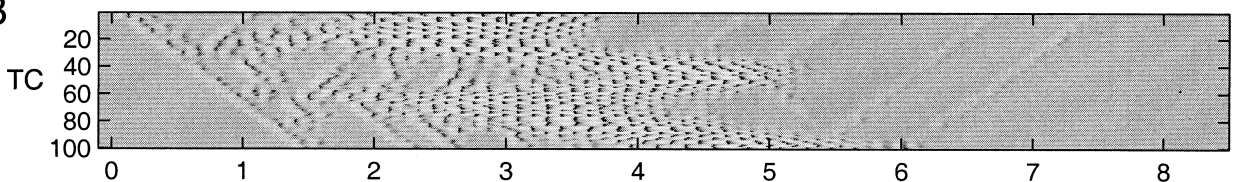

$\mathrm{RE}$
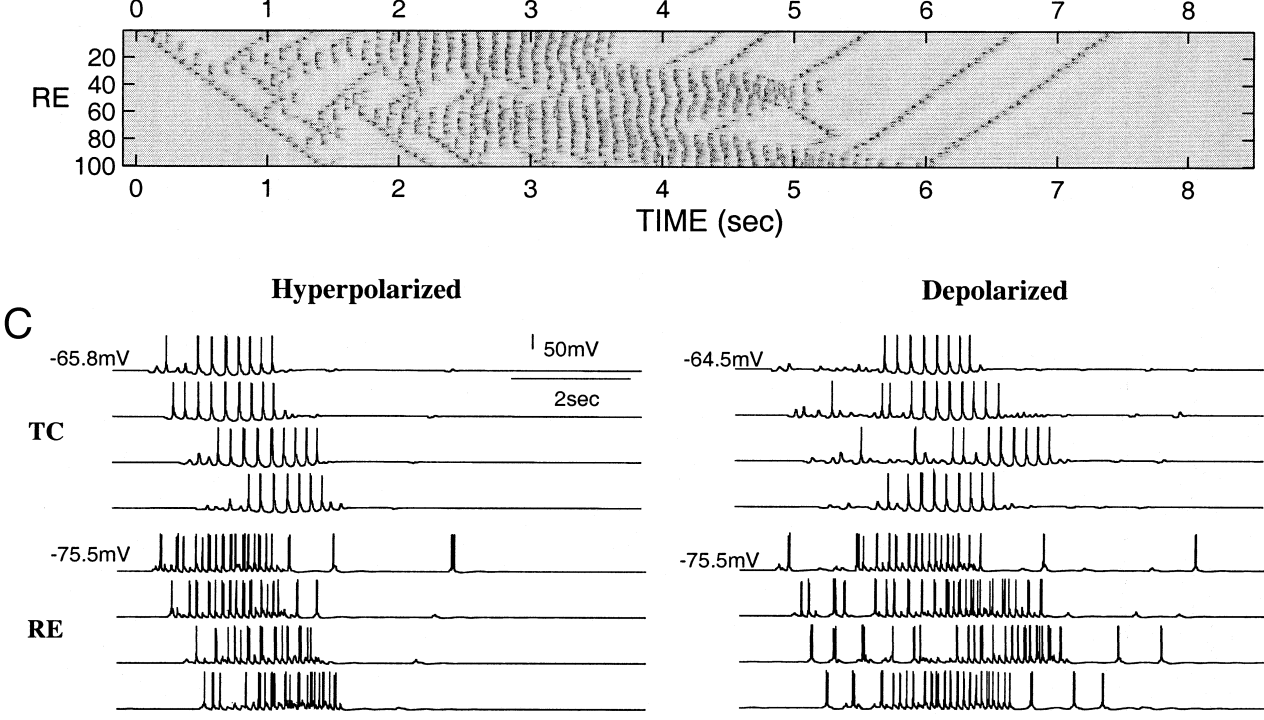

Depolarized

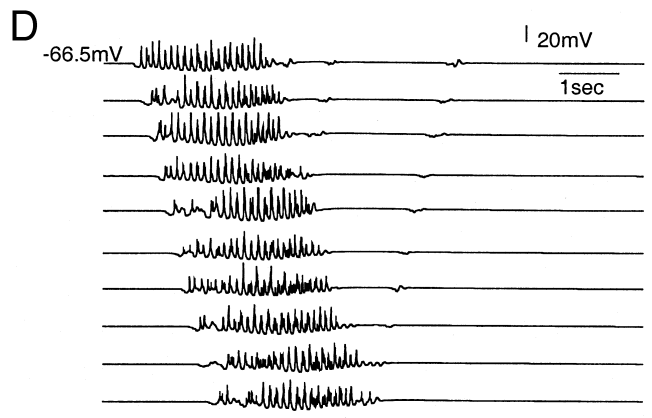

FIG. 4. Network properties of the spindle oscillations in a one-dimensional chain of $2 \times 100$ RE-TC cells. TC cell \#1 from the network was stimulated at the time instant $t=0$. $A$ : hyperpolarized TC network. The single spindle sequence appeared as a result of external stimulation and propagated with constant velocity. $B$ : depolarization of TC cells by about $2-3$ $\mathrm{mV}$ on average reduced the synchrony of spindle sequences. The patterns of activity traveling through the RE network randomly initialized the local spindle sequences at different network foci. $C$ : membrane potentials for four TC and RE cells equidistantly located in the networks shown at panel $A$ (left) and $B$ (right). D: average membrane potentials calculated for 10 equidistantly located groups of 10 neighboring TC cells. were able to trigger a low-threshold spike followed by $\mathrm{Na}^{+}$ spikes that led to a new sequence of spindle oscillations (see Fig. 5).

The new sequence of spindle oscillations might be initiated at several foci of the network as determined by the local properties of RE and TC cells and spread rapidly to the whole network in about $0.5-1 \mathrm{~s}$. Increasing the size of the network up to 200 cells did not change this delay time significantly (see Fig. $5 C$, second spindle sequence), although it took twice as long for the initial stimulation to spread to the whole network. These results indicate that activity persisting in the network of RE cells may significantly change the way that spindle oscillations propagate through the RE-TC network. The sequences of spindle oscillations initiated by the localized patterns sustained in RE network occurred more synchronously compared with the sequences initiated by external stimulus or a pacemaker (spontaneously oscillating) TC cell.

\section{Properties of spindle oscillations}

Sequences of spindle oscillations occur in vivo every 5-15 s. The time interval between two sequences of $10-\mathrm{Hz}$ spindle oscillations in RE-TC network model was in the same range and depended on several parameters.

Figure 6 shows the influence of the intrinsic properties of RE and TC cells and the strength of synaptic interconnections between those cells on the duration of the interspindle lull. This was calculated by first finding the average membrane potentials (field potentials) over $10 \mathrm{TC}$ cells at 10 equally spaced sites. Then, the time interval between the ending and the beginning of continuous 
A
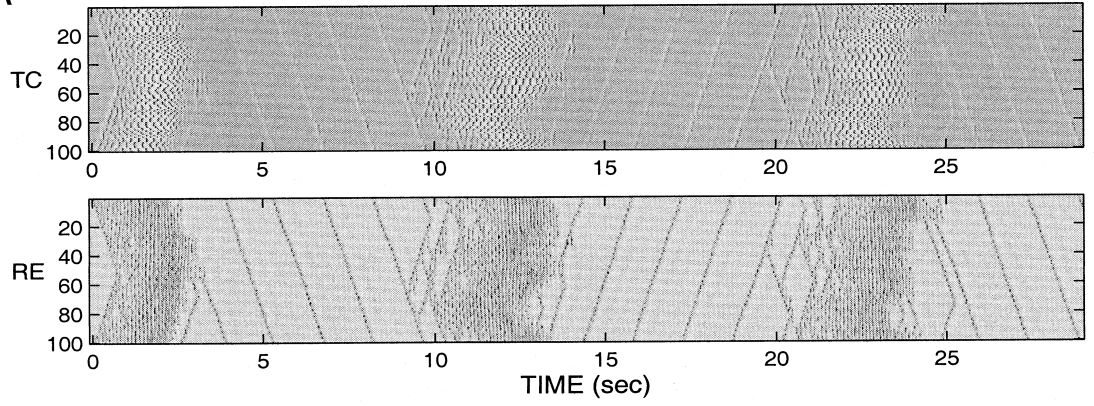

$\mathrm{B}$

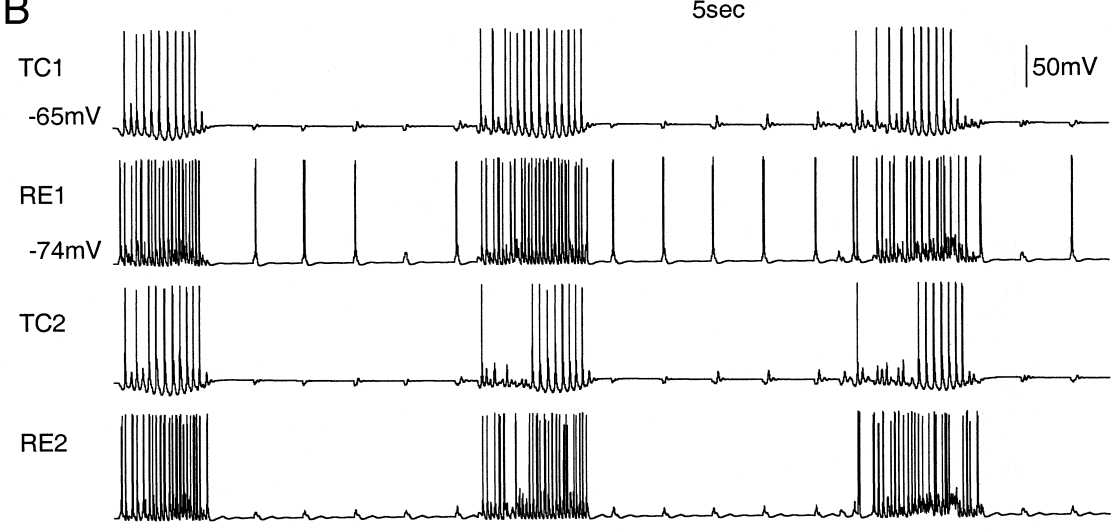

C
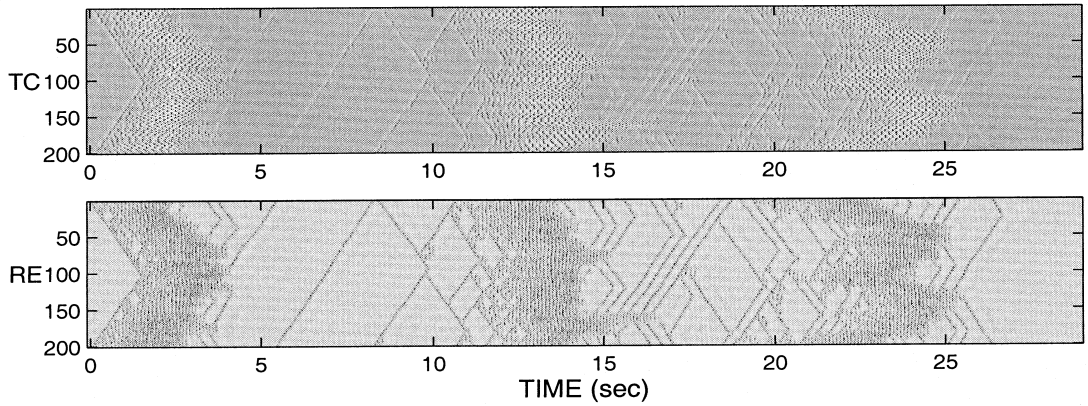

FIG. 5. Initiation of spindle sequences in an RE-TC network with periodic boundary conditions. $A$ : the sequence of spindle oscillations was initiated at $t=0$ by the local stimulation of TC cell \#1 (left upper corner of the panel) and then propagated in both directions with constant velocity. After $2-4 \mathrm{~s}$, the spindle sequence was terminated because of the $\mathrm{Ca}^{2+}$ up-regulation of $I_{\mathrm{h}}$ current and was followed by localized patterns traveling through the RE nuclei. This activity triggered a new spindle sequence at about $t=15 \mathrm{~s}$. $B$ : membrane potentials for two RE-TC pairs. $C$ : spindle oscillations in the network of $2 \times 200$ RE-TC cells. field potential oscillations in the same site was averaged over all 10 sites. Depolarization of the TC network produced by the decrease of $\mathrm{K}^{+}$leak conductance increased the duration of intersequence intervals (see Fig. 6A). A depolarization of 2-3 mV increased the time interval between sequences of spindle oscillations to about $18 \mathrm{~s}$ compared with about $7 \mathrm{~s}$ for a relatively more hyperpolarized TC network (Fig. 5A). The effect of depolarization is a consequence of the slower deinactivation of the low-threshold $\mathrm{Ca}^{2+}$ current in TC cells after spindles that reduced their ability to generate $\mathrm{Ca}^{2+}$ spikes.

Decrease of the $\mathrm{Ca}^{2+}$ conductance in RE cells (Fig. 6B) weakened burst discharges of RE neurons and reduced REevoked IPSPs in TC cells, which increased the time intervals between sequences of spindle oscillations up to $25 \mathrm{~s}$. In contrast, increase of the $\mathrm{Ca}^{2+}$ conductance reduced the duration of the interspindle lulls to about $4 \mathrm{~s}$ (see Fig. 6B, left) and greatly increased the speed of localized clusters propagating through the network between spindle sequences.

Figure $6 C$ shows the effect of changing the $\mathrm{GABA}_{\mathrm{A}}$ coupling between RE and TC cells. Increase of the maximal conductance for $\mathrm{GABA}_{\mathrm{A}}$ RE-TC connections by only about $15 \%$ reduced the time intervals between spindle sequences to about $5 \mathrm{~s}$ (see Fig. 6C, left), but without significantly changing the spatio-temporal patterns of spindle oscillations. In contrast, the depolarization of the TC network reduced the spatial synchrony of the spindle oscillations (see Fig. 6A).

Changing the maximal conductance of the $\mathrm{GABA}_{\mathrm{A}}$ RE-RE synapses produced effects that were opposite to those that occurred when the RE-TC $\mathrm{GABA}_{\mathrm{A}}$ connections were changed (Fig. 6D). Decrease of the maximal conductance for RE-RE synapses reinforced burst discharges in RE cells (see details in Bazhenov et al. 1998) and increased RE-evoked IPSPs in TC cells; this decreased the duration of the time intervals between sequences of spindle oscillations.

Increase of the TC-RE AMPA conductance augmented burst discharges in RE cells and increased $\mathrm{GABA}_{\mathrm{A}}$ IPSPs in TC cells, which reduced interstimulus intervals (Fig. 6E). Thus, both inhibitory and excitatory connections between RE and TC cells affected the length of the interspindle lulls by reinforcing

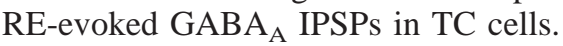


A
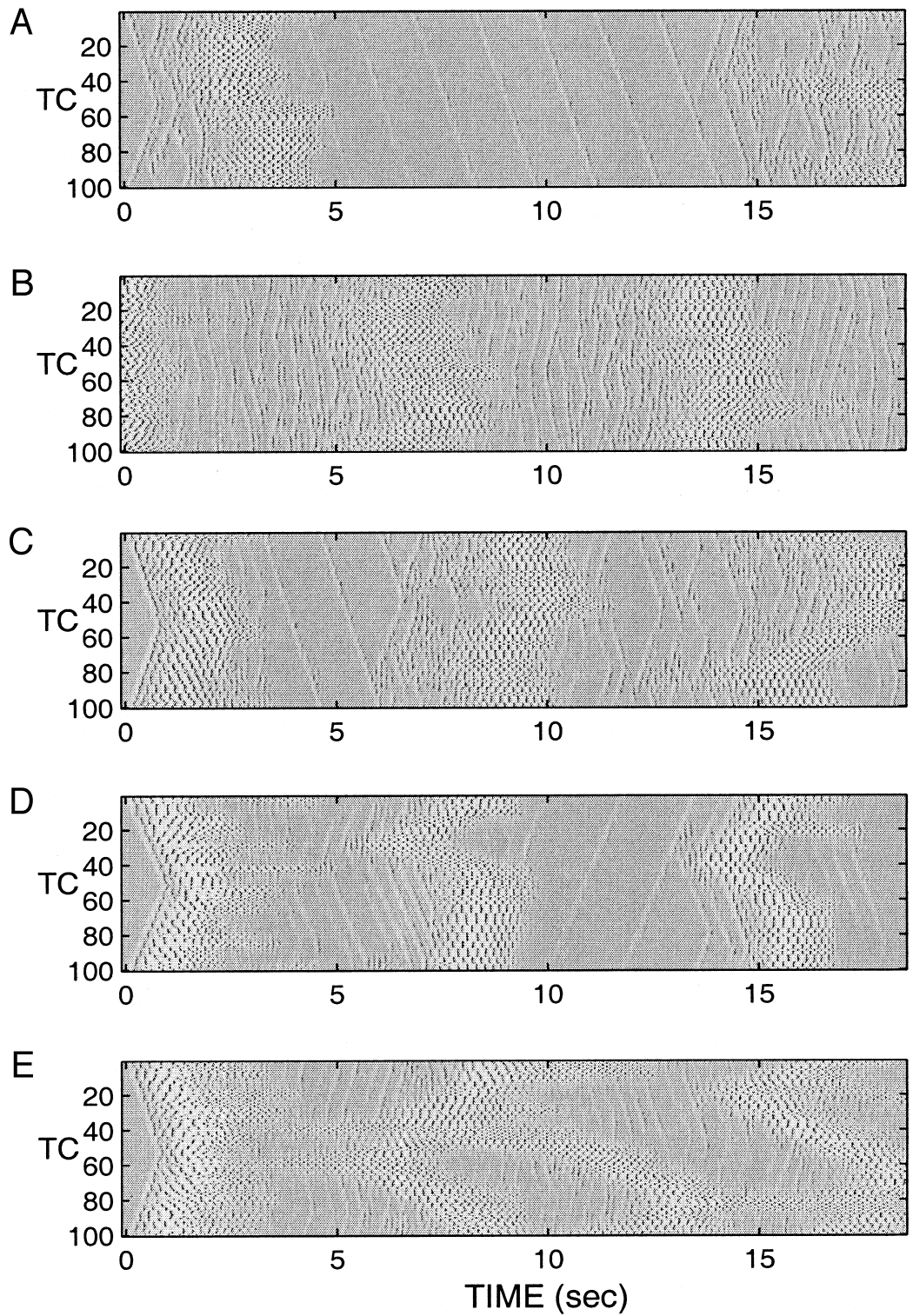
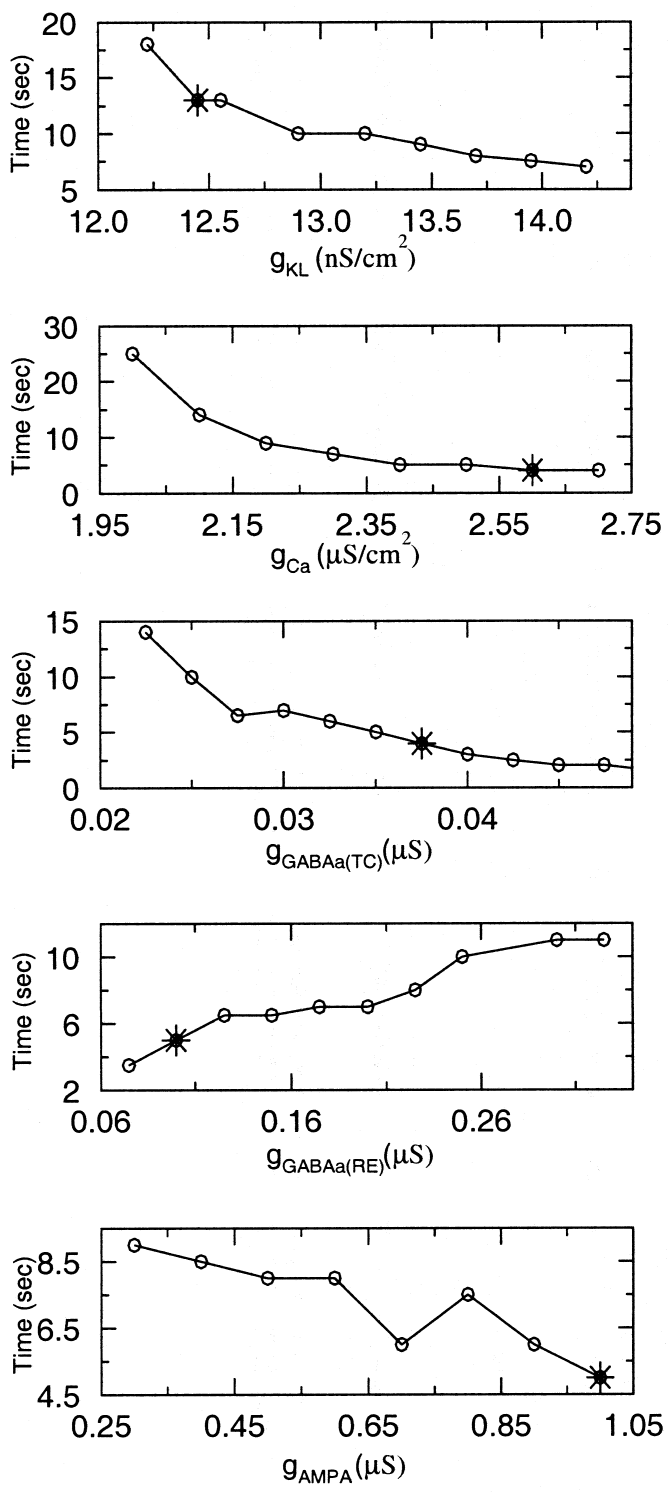

FIG. 6. Effect of the intrinsic and synaptic properties of RE and TC cells on the interspindle duration shown at the right. Spatio-temporal patterns of spindle oscillations corresponding to the conductance values marked by the stars are shown at the left. Parameters are the same as for Fig. $5 A$ except when varied. $A$ : maximal conductance for $\mathrm{K}^{+}$leak current in TC cells $\left(l e f t, g_{\mathrm{KL}}=\right.$ $12.45 \mathrm{nS} / \mathrm{cm}^{2}$ ). B: maximal conductance for $\mathrm{Ca}^{2+}$ current in RE cells (left, $g_{\mathrm{Ca}}=2.6 \mu \mathrm{S} / \mathrm{cm}^{2}$ ). C: GABA $\mathrm{RE}-\mathrm{TC}$ synaptic conductance $\left(l e f t, g_{\mathrm{GABAA}}=0.0375 \mu \mathrm{S}\right) . D: \mathrm{GABA}_{\mathrm{A}}$ RE-RE synaptic conductance $\left(l e f t, g_{\mathrm{GABAA}}=0.1 \mu \mathrm{S}\right)$. E: AMPA TC-RE synaptic conductance $\left(\right.$ left, $\left.g_{\mathrm{AMPA}}=1.0 \mu \mathrm{S}\right)$.

\section{Two-dimensional RE-TC model}

In an isolated two-dimensional network of RE cells hyperpolarized below the $\mathrm{Cl}^{-}$reversal potential, self-sustained patterns of spiking-bursting activity appeared in the form of spiral waves (Bazhenov et al. 1999). The dynamics of a twodimensional $25 \times 25$ RE-TC network is investigated here (MPEG-1 movie is available at http://tesla.salk.edu/ bazhenov/ simulations.html).

Figure $7 A$ shows a sequence of activity snapshots in TC (Fig. 7A1) and RE (Fig. 7A2) networks. Time traces of two arbitrarily selected RE and TC cells are shown in Fig. 7B. A single stimulus applied to the RE cell $\#(1,1)$ at time instant $t=$ 0 (first panels in Fig. 7A) initiated a sequence of spindle oscillations that propagated through the network. After about
$0.7 \mathrm{~s}$, all RE and TC cells were involved in the oscillations. The second panel at $t=1.5 \mathrm{~s}$ (Fig. 7A) shows typical network activity during a spindle. The large orange regions of the RE network correspond to synchronous bursting of RE cells. Because the TC cells burst every second cycle in the spindle oscillations, no more than $50 \%$ of the TC cells could fire at any given time; the red clusters indicate those of TC cells that were active at $t=1.5 \mathrm{~s}$ during a spindle (Fig. 7A).

The first sequence of spindle oscillations in the two-dimensional RE-TC network in Fig. 7 terminated after about $2.7 \mathrm{~s}$. The next five panels in Fig. 7 (from $t=4.48 \mathrm{~s}$ until $t=13.44$ s) illustrate the network behavior between two spindle sequences. During this phase of oscillations, the localized waves of activity traveled through the RE network and led occasion- 
A
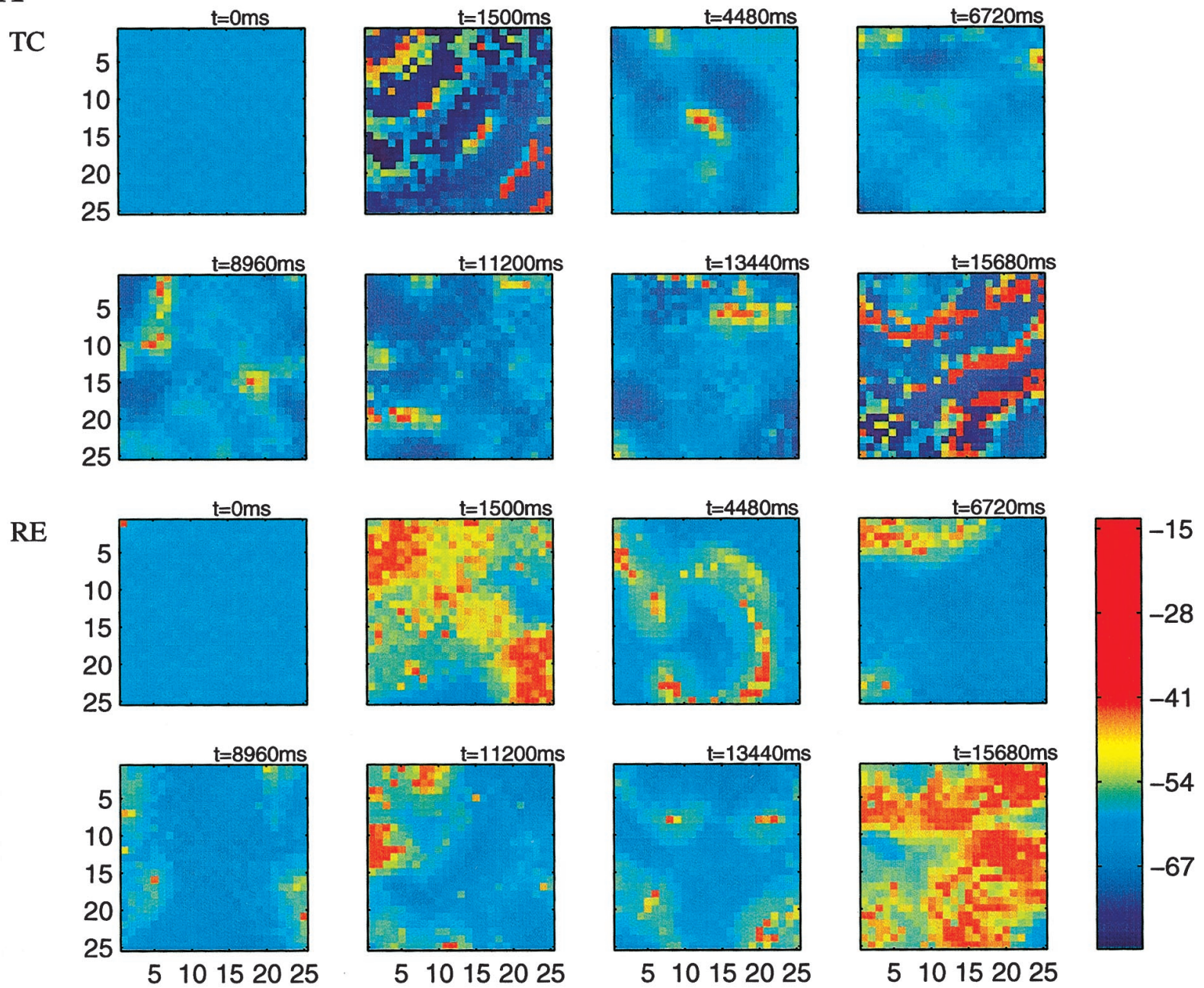

B

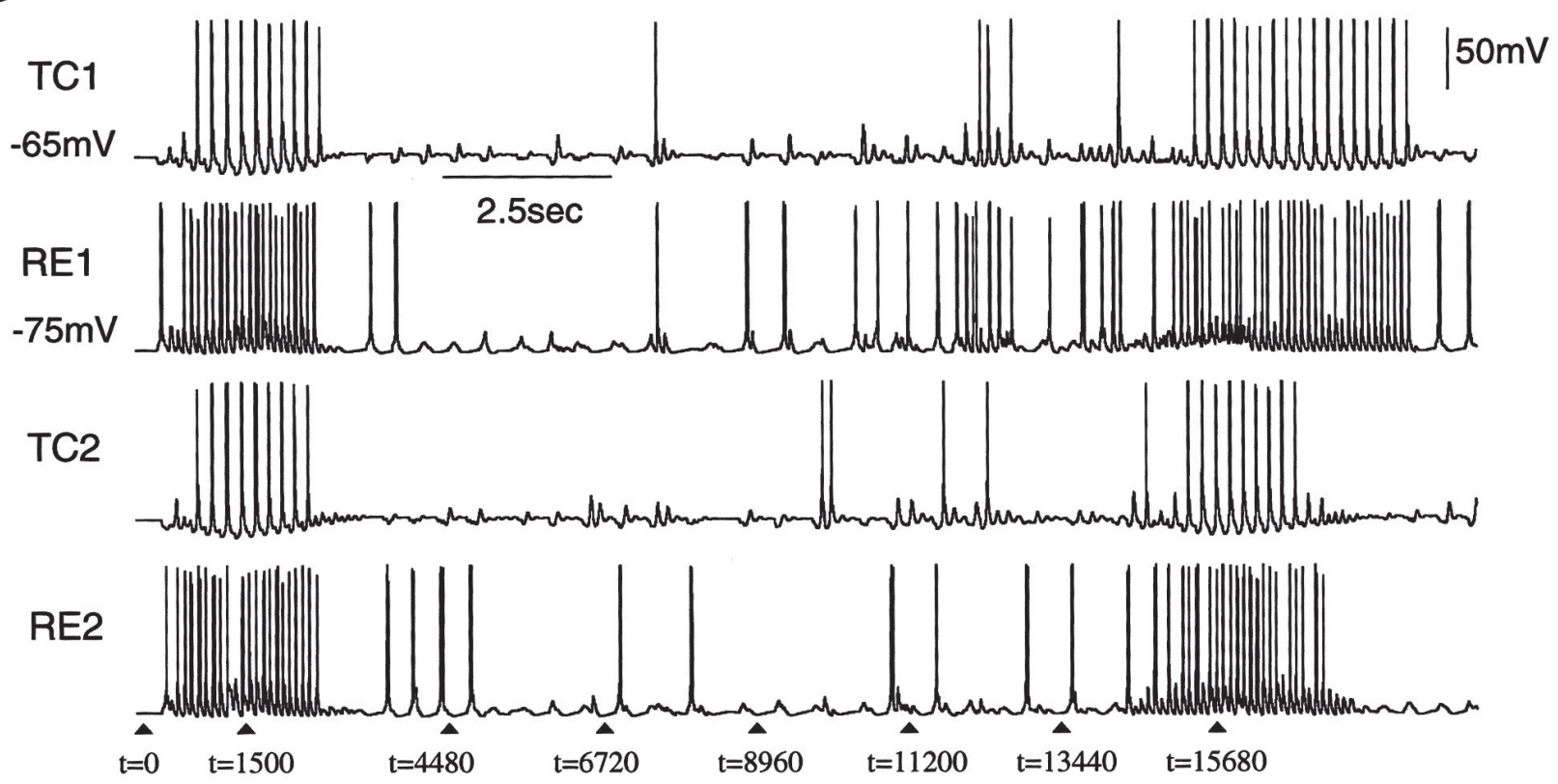

FIG. 7. Spindle oscillations in the two-dimensional RE-TC network. TC cell \#(1,1) from the network of $2 \times 25 \times 25$ RE-TC cells was stimulated at the time $t=0$. A: snapshots of the population activity in TC (top) and RE (bottom) networks at different time points. Color bar indicates membrane potential. $B$ : the membrane potentials of two representative RE and TC cells [\# $(3,12)$ and \#(12,12)]. 
ally to the spike bursts in the small clusters of TC cells. Analysis of the time traces of individual RE cells (Fig. 7B) showed that 3-Hz oscillations dominated during first 2-3 s after the spindle sequence with the influence of TC cells diminished. After 3-4 s, some TC cells started to respond with $\mathrm{Na}^{+}$spikes to the RE-evoked IPSPs, but this did not lead to the new spindle sequences (see Fig. 7B). A new sequence of $10-\mathrm{Hz}$ oscillations initiated only after the membrane potentials of most of TC cells repolarized below about $-64 \mathrm{mV}$ (see last panel of Fig. $7 A, t=15.68 \mathrm{~s}$ ). As observed in the onedimensional network, the duration of spindle oscillations in the two-dimensional model was slightly different at different network foci (see Fig. 7B). Also, some of the TC cells repolarized faster than others, so spatially localized sequences of spindle oscillations were initiated randomly, before the whole network became involved in synchronous $10-\mathrm{Hz}$ oscillations. Note that the amplitude of local depolarizing potentials observed in TC cells during interspindle lull exceeded those typically recorded in vivo (Fig. $2 B$ ). TC cells were slightly more hyperpolarized in the model compared with in vivo data and RE spikes triggered partial low-threshold spikes in the postsynaptic TC cells.

Depolarizing potentials in RE cells during an interspindle lull occurred at frequencies around $3 \mathrm{~Hz}$. This frequency was determined by the spatio-temporal properties of the rotating spiral waves that persisted in the RE network (see e.g., snapshot of RE cells at $t=4480 \mathrm{~ms}$ on Fig. 7A; also see details in Bazhenov et al. 1999). Periodic excitation led to the bursting; however, sequences usually consisted of $<4$ sequential bursts, which reflects partial inactivation of the low-threshold $\mathrm{Ca}^{2+}$ current in RE cells during intense bursting. In in vivo recordings, the frequency of bursting was similar, but, only single bursts or doublets of bursts were recorded (see Fig. $2 B$ ). Other mechanisms, such as synaptic depression or/and movement of the spiral core, could further reduce the duration of continuous bursting in local groups of RE cells in vivo.

\section{I S C US S I O N}

The patterns of spindles and their synchronization are not identical in the intact brain and in thalamic slices. The depolarizing plateau of the spindle envelope recorded from thalamic RE neurons in vivo (Deschenes et al. 1984) was not initially observed in RE neurons from ferret slices that, instead, displayed a sustained hyperpolarization during spindles (Krosigk et al. 1993). This difference may be due to lack of brainstem activating systems and corticothalamic depolarizing inputs in thalamic slices. More recently, recordings in thalamic slices (Kim and McCormick 1998) revealed depolarizing plateaus in about half of recorded RE neurons during spindles at membrane potentials closer to those recorded in vivo. Spindles have been reported in the deafferented RE nucleus in vivo (Steriade et al. 1985) but are absent in vitro (Krosigk et al. 1993). The hypothesis that dendro-dendritic inhibitory synapses between $\mathrm{RE}$ cells is the major mechanism for generating spindles in the deafferented RE nucleus in vivo was recently tested intracellularly. It was found that reversed IPSPs between RE neurons can directly trigger low-threshold spikes followed by bursts at membrane potentials close to those seen during natural sleep (Bazhenov et al. 1999). One major difference between in vivo and in vitro conditions is that the long dendrites and axonal collaterals of RE neurons are, in all likelihood, cut when slices are prepared and modulatory systems arising in the brainstem are absent in thalamic slices. The depolarization of RE neurons by inputs arising in monoamine-containing systems, such as the serotonin released by dorsal raphe afferents and noradrenaline released by locus coeruleus afferents, promotes the sensitivity of RE neurons to the IPSPs generated by intra-RE GABAergic connections, with the consequence of generating spontaneous oscillations within the frequency range of spindles (Destexhe et al. 1994a). In 2D network simulations (Destexhe et al. 1994b), RE neurons organized with "dense proximal connectivity" were examined in a hyperpolarized state ( -65 to $-75 \mathrm{mV}$ ), similar to the in vitro condition when no monoaminergic synapses are activated, and in a more depolarized state $(-60$ to $-70 \mathrm{mV})$ that would correspond to a weak monoaminergic activity. In the latter condition, RE neurons generated spindle-like oscillations, whereas in the former condition, the oscillatory behavior was absent.

Recent intracellular recordings from RE neurons in vivo as well as computational modeling of an isolated RE network indicate that reversed IPSPs between RE cells can directly trigger a low-threshold spike (Bazhenov et al. 1999). In a one-dimensional RE network hyperpolarized below $\mathrm{Cl}^{-}$reversal potential, the $\mathrm{GABA}_{\mathrm{A}}$-mediated depolarization initiated isolated patterns of spike-burst activity that traveled through the RE network with a velocity that depended on the intrinsic and synaptic properties. The factors that especially affected the speed of propagation were the radius of synaptic interconnections and strength of $\mathrm{GABA}_{\mathrm{A}}$ synapses between RE cells (Bazhenov et al. 1999). Similar patterns were described in some other network models (Ermentrout 1998; Golomb and Amitai 1997; Golomb and Ermentrout 1999). In a two-dimensional model of RE network, activity persisted in the form of rotating spiral waves if the network size was large enough (Bazhenov et al. 1999). It produced almost periodic bursting in RE cells at a frequency of about $3 \mathrm{~Hz}$. When the resting potential of RE neurons was depolarized more closely to the $\mathrm{Cl}^{-}$reversal potential, the frequency of spontaneous oscillations increased up to about $10 \mathrm{~Hz}$. In the spiral-wave mode, RE cells placed at different network foci fired with a constant phase shift, which depended on their relative location. Thus, this network state may be synchronized, but in an essentially different way from simple in-phase or anti-phase oscillations previously described in the isolated RE networks (Destexhe et al. 1994b; Wang and Rinzel 1993). It is likely that multi-spiral states will be observed in the much larger networks of isolated $\mathrm{RE}$ cells, so the large-scale synchrony of RE oscillations will be limited to within the domains of individual spirals.

In the RE-TC network, each sequence of spindle oscillations was followed by a few localized patterns of activity propagating inside the population of RE cells. These patterns could not trigger bursts of $\mathrm{Na}^{+}$spikes in the TC cells, which were depolarized after the spindle sequence, until the slow repolarization of TC cells deinactivated the low-threshold $\mathrm{Ca}^{2+}$ current and the local RE-evoked IPSPs could initiate a new sequence of spindle oscillations (see Fig. 3). The time interval between the sequences of spindle oscillations ranged from 2 to $20 \mathrm{~s}$ depending on the intrinsic properties of RE and TC cells as well as on the strengths of synaptic interconnections between the cells (Fig. 6).

Spatio-temporal patterns of spindle oscillations initiated by 
local stimulation of the silent RE-TC network were different from those triggered by the waves of spike-burst activity persisting in the RE network. In the former case, the spindle oscillations started at the focus of stimulation and propagated with constant velocity through the network. The time delay between the time of initiation or termination of the spindle sequences in two different network foci was proportional to the distance between them. In contrast, the waves of activity propagating in the RE nucleus, might initiate, almost simultaneously, local sequences of spindle oscillations at different spatially separated network foci. Some of these local sequences terminated after 1-2 cycles of oscillations but they could also initiate new patterns. The rapid spread of activity occurred through the more or less synchronous activation of the spindle oscillations in distant network foci (see Fig. 5C). The depolarization of TC cells reduced the spatial synchrony of spindle sequences, but it also increased the number of activity patterns following each spindle sequence (see Fig. 4) and made the new spindle sequences more homogeneous over the large population of RE and TC cells.

Hyperpolarization below the $\mathrm{Cl}^{-}$reversal potential was necessary to maintain the spiking-bursting activity observed in the RE network during interspindle lulls but it did not change the spatio-temporal patterns of spindle oscillations. In fact, during $10-\mathrm{Hz}$ spindle oscillations, activation of the lateral GABA interconnections inhibited target RE cells. At each cycle of oscillations, TC-evoked EPSPs mediated more or less synchronous depolarization of RE cells above the $\mathrm{Cl}^{-}$reversal potential. This led to burst discharges in some RE neurons that in turn evoked normal (not reversed) IPSPs in postsynaptic RE cells. Thus there is an important difference between the properties of the RE network hyperpolarized below $\mathrm{Cl}^{-}$reversal potential and networks with purely excitatory (e.g., AMPAmediated) interconnections. Excitatory synaptic coupling supports different types of synchronous patterns including traveling clusters of spiking-bursting activity (Golomb 1998; Golomb and Amitai 1997). Also, the oscillations in excitatory networks may be transformed easily into highly synchronous epileptic-like activity if the synaptic interconnections are strong enough (Hansel et al 1995). In networks of RE cells hyperpolarized below the $\mathrm{Cl}^{-}$reversal potential, $\mathrm{GABA}_{\mathrm{A}^{-}}$ mediated depolarization produced localized structures that were similar to the patterns in the purely excitatory networks. However, the same synapses mediated lateral inhibition when the RE cells started to fire synchronously. This mechanism "protects" the network against highly synchronous activity. Thus, the relatively hyperpolarized RE network may combine important properties of both excitatory and inhibitory neural networks.

Thalamic interneurons (INs) are an additional source of the inhibitory input for TC cells. We tested their effect in the RE-TC network model and found that if INs were depolarized with DC current enough to initiate spontaneous firing, their firing rate decreased during a spindle through inhibitory inputs from RE neurons. The decreased activity of INs due to inhibitory inputs from RE neurons is consistent with previous experimental data showing that after disconnection from RE neurons, there is an increased incidence of IPSPs in TC neurons due to the disinhibition of INs (Steriade et al. 1985). The projections from RE neurons to INs have been documented anatomically (Liu et al. 1995). Thalamic INs display robust burst firing when a depolarizing sag is imposed at a slightly hyperpolarized membrane potential as well as oscillatory activity within the frequency range of $5-15 \mathrm{~Hz}$ (Zhu et al. 1999a,b). Diminishing the IN-evoked inhibition in TC cells evoked additional depolarization of the TC neurons, which reduced the length of the interspindle periods. Although strong spontaneous activity of INs during resting sleep is unlikely, it is possible that INs can contribute to spindle control at more depolarized levels of the network oscillations during transition to the awake state.

In a previous model of spindle oscillations, new spindle sequences were triggered by spontaneously oscillating (initiator) TC cells (Destexhe et al. 1996). In the RE-TC network model studied here, the cells were almost identical and the small variability in the intrinsic properties were not strong enough to make any of them a pacemaker. As a result, a sequence of spindle oscillations may be triggered either by the external stimulation or by localized waves traveling inside the RE network. In a one-dimensional RE-TC model, periodic boundary conditions were used to keep waves traveling long enough to initiate a new spindle sequence. However, in a large-scale two-dimensional model of the reticular nucleus, activity in the RE network was self-sustained $2-10 \mathrm{~Hz}$ oscillations, which were controlled by the maximum conductance of the low-threshold $\mathrm{Ca}^{2+}$ current and the level of membrane potential (Bazhenov et al. 1999). In a two-dimensional model of RE-TC network, this activity persisted in the RE network during interspindle lulls and triggered new sequences of spindle oscillations involving both RE and TC cells. The waves of the spike-burst activity propagating inside the RE network were reflected in the bursts of $\mathrm{Na}^{+}$spikes that appeared in individual RE cells in the frequency range from 2 to $3 \mathrm{~Hz}$ (see Fig. 7). The same type of activity has been recorded extracellularly from RE nucleus during interspindle lulls (see Fig. 1).

Several predictions of the model can be tested experimentally. First, the decrease in potassium leak current resulted in depolarization of TC neurons and in the increase in interspindle intervals (Fig. 6A). This may reflect conditions during the early periods of sleep when the level of ACh is still relatively high, the TC neurons are relatively depolarized, and the intra-spindle periods are relatively long. These spindles might not even be seen in extracellular recordings from dorsal thalamus or from cortex, because synchronization between depolarized TC neurons is low and they may display only IPSPs of RE origin that do not result in spike bursts. This prediction may be tested by intracellular recordings from TC neurons during the natural sleep-wake cycle. Second, an increase in $\mathrm{GABA}_{\mathrm{A}}$ RE-TC connection reduced the time intervals between spindle sequences. This prediction indicates that the use of benzodiazepines or other drugs affecting $\mathrm{GABA}_{\mathrm{A}}$ synaptic transmission may result in significant shortening in the time between spindles. However, such drugs will also affect the RE-RE and intracortical IPSPs, dramatically changing the global synchronization in thalamocortical network. The relative impact of

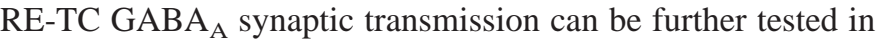
a global thalamocortical model of slow-wave sleep, in in vivo experiments with local intrathalamic infusion of $\mathrm{GABA}_{\mathrm{A}}$ facilitating agents or in transgenic experimental models.

In a two-dimensional RE-TC network model, new spindle sequences were initiated at many network foci almost simultaneously. Recently, it was shown in vivo and in a computa- 
tional model that the corticothalamic feedback can contribute to the synchrony of the spindle oscillations in vivo (Destexhe et al. 1998). The wide divergence of the corticothalamic connections recruits large thalamic areas on each cycle of the spindle oscillation and provides a mechanism for spreading the spindle activity more rapidly than in the isolated thalamus. A combination of the corticothalamic feedback with an RE-dependent mechanism for spindle initiation can provide even more coherent spindle activity over a larger population of RE and TC cells. Thus, our model predicts that the corticothalamic network has an intrinsic mechanism contributing to the synchrony of in vivo spindle oscillations.

This research was supported by the Howard Hughes Medical Institute; the Sloan Center for Theoretical Neurobiology, Human Frontier Science Program; and the Medical Research Council of Canada.

\section{REFERENCES}

BAL T AND MCCORMICK DA. What stops synchronized thalamocortical oscillations? Neuron 17: 297-308, 1996

Bazhenov M, Timofeev I, Steriade M, and Sejnowski TJ. Cellular and network models for intrathalamic augmenting responses during $10 \mathrm{~Hz}$ stimulation. J Neurophysiol 79: 2730-2748, 1998.

Bazhenov M, Timofeev I, Steriade M, and Sejnowski TJ. Self-sustained rhythmic activity in the thalamic reticular nucleus mediated by depolarizing GABA $_{A}$ receptor potentials. Nature Neurosci 2: 168-174, 1999.

Budde T, Biella G, Munsch T, and PAPE HC. Lack of regulation by intracellular $\mathrm{Ca}^{2+}$ of the hyperpolarization-activated cation current in rat thalamic neurons. J Physiol (Lond) 503: 79-85, 1997.

Contreras D, Destexhe A, Sejnowski TJ, and Steriade M. Control of spatiotemporal coherence of a thalamic oscillation by corticothalamic feedback. Science 274: 771-774, 1996.

Deschenes M, Paradis M, Roy JP, and Steriade M. Electrophysiology of neurons of lateral thalamic nuclei in cat: resting properties and burst discharges. J. Neurophysiol 51: 1196-1219, 1984.

Destexhe A, Bal T, McCormick DA, AND SeJnowski TJ. Ionic mechanisms underlying synchronized oscillations and propagating waves in a model of ferret thalamic slices. J Neurophysiol 76: 2049-2070, 1996.

Destexhe A, Contreras D, Sejnowski TJ, and Steriade M. Modeling the control of reticular thalamic oscillations by neuromodulators. Neuroreport 5: 2217-2220, 1994a.

Destexhe A, Contreras D, Sejnowski TJ, and Steriade M. A model of spindle rhythmicity in the isolated thalamic reticular nucleus. $J$ Neurophysiol 72: 803-818, 1994b.

Destexhe A, Contreras D, and Steriade M. Mechanisms underlying the synchronizing action of corticothalamic feedback through inhibition of thalamic relay cells. J Neurophysiol 79: 999-1016, 1998.

Destexhe A, Mainen ZF, and Sejnowski TJ. Synthesis of models for excitable membranes, synaptic transmission and neuromodulation using a common kinetic formalism. J Comp Neurosci 1: 195-230, 1994.

Dutar P AND Nicoll RA. A physiological role for $\mathrm{GABA}_{\mathrm{B}}$ receptors in the central nervous system. Nature 332: 156-158, 1988.

ENRIGHT WH, Higham DJ, OWRen B, AND ShaRp PW. A survey of the explicit Runge-Kutta method [Online]. ftp://ftp.cs.toronto.edu/pub/reports/na/cs-94291:ps.Z [1995].

ERMENTROUT GB. The analysis of synaptically generated traveling waves. J Comp Neurosci 5: 191-208, 1998.

GoLOMB D. Models of neuronal transient synchrony during propagation of activity through neocortical circuitry. J Neurophysiol 79: 1-12, 1998.

Golomb D and AmitaI Y. Propagating neuronal discharges in neocortical slices: computational and experimental study. J Neurophysiol 78: 1199_ 1211, 1997.
Golomb D And ERmentrout GB. Continuous and lurching traveling pulses in neuronal networks with delay and spatially decaying connectivity. Proc Natl Acad Sci USA 96: 13480-13485, 1999.

Hansel D, Mato G, and Meunier C. Synchrony in excitatory neural networks. Neural Comput 7: 307-337, 1995.

HugUENARD JR AND MCCORMICK DA. Simulation of the currents involved in rhythmic oscillations in thalamic relay neurons. J Neurophysiol 68: 1373$1383,1992$.

Huguenard JR AND PRINCE DA. A novel T-type current underlies prolonged $\mathrm{Ca}^{2+}$-dependent burst firing in GABAergic neurons of rat thalamic reticular nucleus. J Neurosci 12: 3804-3817, 1992.

Kim U AND McCormick DA. Functional and ionic properties of a slow afterhyperpolarization in ferret perigeniculate neurons in vitro. $J$ Neurophysiol 80: 1222-1235, 1998.

von Krosigk M, Bal T, AND McCormick DA. Cellular mechanisms of a synchronized oscillation in the thalamus. Science 261: 361-364, 1993.

Liu XB, WarRen RA, AND Jones EG. Synaptic distribution of afferents from reticular nucleus in ventroposterior nucleus of cat thalamus. J Comp Neurol 352: $187-202,1995$

LÜTHI A, BAL B, AND MCCORMICK DA. Periodicity of thalamic spindle waves is abolished by ZD7288, a blocker of Ih. J Neurophysiol 79: 3284-3289, 1998.

LÜTHI A AND MCCORMICK DA. Modulation of a pacemaker current through $\mathrm{Ca}(2+)$-induced stimulation of cAMP production. Nature Neurosci 2: 634641, 1999.

MCCORMICK DA AND PAPE HC. Properties of a hyperpolarization-activated cation current and its role in rhythmic oscillation in thalamic relay neurons. J Physiol (Lond) 431: 291-318, 1990.

RisPal-Padel L, HaRnoIS C, and TROIANI D. Converging cerebellofugal inputs to the thalamus. I. Mapping of monosynaptic field potentials in the ventrolateral nucleus of the thalamus. Exp Brain Res 68: 47-58, 1987a.

Rispal-Padel L, TROIANi D, and HaRnoIs C. Converging cerebellofugal inputs to the thalamus. II. Analysis and topography of thalamic EPSPs induced by convergent monosynaptic interpositus and dentate inputs. Exp Brain Res 68: 59-72, 1987b.

Steriade M, Deschênes M, Dominich L, and Mulle C. Abolition of spindle oscillations in thalamic neurons disconnected from nucleus reticularis thalami. J Neurophysiol 54: 1473-1497, 1985.

Steriade M, Domich L, OAKson G, and Deschênes M. The deafferented reticular thalamic nucleus generates spindle rhythmicity. J Neurophysiol 57: 260-273, 1987.

STERIADE M, JonEs EG, AND LuINÁs RR. Thalamic Oscillations and Signaling. New York: Wiley-Interscience, 1990.

StERIADE M AND Llinás RR. The functional states of the thalamus and the associated neuronal interplay. Physiol Rev 68: 649-742, 1988

Steriade M, McCormick DA, and Sejnowski TJ. Thalamocortical oscillations in the sleeping and aroused brain. Science 262: 679-685, 1993.

Timofeev I AND STERIADE M. Fast (mainly $30-100 \mathrm{~Hz}$ ) oscillations in the cat cerebellothalamic pathway and their synchronization with cortical potentials. J Physiol (Lond) 504: 153-168, 1997.

Traub RD and Miles R. Neuronal Networks of the Hippocampus. Cambridge, UK: Cambridge Univ. Press, 1991.

UlRiCh D AND HuguenaRd JR. g-Aminobutyric acid type B receptor-dependent burst-firing in thalamic neurons: a dynamic clamp study. Proc Natl Acad Sci USA 93: 13245-13249, 1996.

UlRICH D AND HuguenARD JR. Nucleus-specific chloride homeostasis in rat thalamus. J Neurosci 17: 2348-2354, 1997.

WANG XJ AND RINZEL J. Spindle rhythmicity in the reticularis thalami nucleus: synchronization among mutually inhibitory neurons. Neuroscience 53: 899904, 1993.

Zhu JJ, LytTon WW, Xue JT, AND UhlRich DJ. An intrinsic oscillation in interneurons of the rat lateral geniculate nucleus. J Neurophysiol 81: 702_ 711, 1999a.

ZHU JJ, UhLRICH DJ, AND LYTTON WW. Burst firing in identified rat geniculate interneurons. Neuroscience 91: 1445-1460, 1999b. 